\title{
CONTAMINAÇÃO DA MICROBACIA DE CAETÉS COM METAIS PESADOS PELO USO DE AGROQUÍMICOS ${ }^{1}$
}

\author{
JAIR FELIPE GARCIA PEREIRA RAMALHO ${ }^{2}$, NELSON MOURA BRASIL DO AMARAL SOBRINHO \\ EARY CARLOS XAVIER VELLOSO ${ }^{4}$
}

\begin{abstract}
RESUMO - Com o objetivo de avaliar a contaminação do solo, sedimentos, água e plantas por metais pesados, decorrente do uso de agroquímicos, na microbacia de Caetés em Paty do Alferes, RJ, amostras de solo foram analisadas, em 1996, para obter os teores totais de $\mathrm{Cd}, \mathrm{Co}, \mathrm{Cu}, \mathrm{Mn}, \mathrm{Ni}, \mathrm{Pb}$ e $\mathrm{Zn}$ de duas áreas com diferentes declividades ( $25 \%$ e $45 \%$ ) tendo, ambas, como cobertura vegetal, capoeira, pasto e olericultura. Os resultados referentes aos solos sob pastagem (antiga área de olericultura) mostraram maiores teores de metais pesados do que a área de capoeira. Entretanto, esses valores não atingiram níveis críticos no solo, e esses elementos estavam presentes em formas químicas pouco disponíveis para absorção pelas plantas, como foi constatado na análise de metais pesados em tomate (Lycopersicum esculentum L.), pimentão (Capsicum annuum L.), repolho (Brassica oleracea L.) e pepino (Cucumis sativus L.), que apresentaram níveis baixíssimos desses elementos. Nas amostras de sedimentos, o comportamento dos metais pesados foi semelhante ao obtido nos solos, estando esses elementos distribuídos em maior porcentagem nas frações residual, ligadas a óxidos de $\mathrm{Mn}$ e Fe e ligadas à matéria orgânica. As amostras de água do córrego e do açude que cortam a microbacia apresentaram valores acima dos padrões internacionais com relação a $\mathrm{Cd}, \mathrm{Pb}$ e $\mathrm{Mn}$.
\end{abstract}

Termos para indexação: contaminação química, pesticidas, elementos metálicos, poluição, solo, sedimento, água, hortaliças.

\section{HEAVY METALS CONTAMINATION OF A WATERSHED IN CAETÉS BY THE USE OF AGROCHEMICALS}

\begin{abstract}
To evaluate heavy metals contamination of soil, sediments, water and plants of the Caetés watershed, in Paty do Alferes, RJ, Brazil, by the use of agrochemicals, samples from two areas with different declivities ( $25 \%$ and $45 \%$ ) were analysed, in 1996, for total contents of $\mathrm{Cd}, \mathrm{Co}, \mathrm{Cu}, \mathrm{Mn}$, $\mathrm{Ni}, \mathrm{Pb}$ and $\mathrm{Zn}$. The results for the soils under pasture (lately horticulture) showed higher heavy metals contents in comparison to the brushwood area. However, these contents didn't reach the critical levels for soils, and these elements were present in chemical forms of low disponibility for plant absorption, as it was seen in the very low levels of heavy metals in the samples of tomato (Lycopersicum esculentum L.), green pepper (Capsicum annum L.), cabbage (Brassica oleracea L.) and cucumber (Cucumis sativus L.). The behaviour of the heavy metals in the sediment samples were the same of the soil samples, being these elements distributed, in higher percentages, in the residual, bonded to $\mathrm{Mn}$ and Fe oxides and bonded to organic matter fractions. The water samples from the stream and dam showed higher levels than the international standards for $\mathrm{Cd}, \mathrm{Pb}$ and $\mathrm{Mn}$.
\end{abstract}

Index terms: chemical contamination, pesticides, metallic elements, pollution, soil, sediment, water, vegetables.

${ }^{1}$ Aceito para publicação em 15 de julho de 1999 Extraído da tese de doutorado apresentada pelo primeiro autor à Universidade Federal Rural do Rio de Janeiro (UFRRJ).

${ }^{2}$ Eng. Agrôn., Ph.D., Campus Dr. Leonel Miranda, UFRRJ, Estrada do Açúcar, s/n, km 5, CEP 28020-560 Campos dos Goytacazes, RJ. E-mail: jframalho@rol.com.br

${ }^{3}$ Eng. Agrôn., Dr., Prof. Titular, Dep. de Solos, UFRRJ, Antiga Rio-São Paulo, km 47, CEP 23851-970 Seropédica, RJ.

${ }^{4}$ Eng. Agrôn., Dr., Prof. Titular, CCTA, Universidade Estadual do Norte Fluminense (UENF), Av. Francisco Lamego, 2000, CEP 28015-620 Campos dos Goytacazes, RJ

\section{INTRODUÇÃO}

A aplicação de agroquímicos aos solos e culturas se tornou uma prática comum na agricultura. Os principais objetivos do uso desses agroquímicos são o aumento do suprimento de nutrientes, correção do $\mathrm{pH}$ do solo (fertilizantes e corretivos) e a proteção das lavouras pelo controle de doenças e pragas (agrotóxicos). Essas práticas podem causar degradação química do solo, como resultado do 
acúmulo de elementos e/ou compostos tóxicos em níveis indesejáveis.

Gimeno-García et al. (1996) estudaram a incidência de metais pesados, como impurezas de fertilizantes e pesticidas aplicados aos solos agrícolas, tendo encontrado que as adições mais significativas foram de $\mathrm{Mn}, \mathrm{Zn}$, Co e $\mathrm{Pb}$. Os fertilizantes minerais e orgânicos, bem como os corretivos de solo contêm $\mathrm{Zn}$, freqüentemente como impureza (Kiekens, 1990). As concentrações de $\mathrm{Zn}$ em fertilizantes fosfatados variam de 50-1.450 $\mathrm{mg} \mathrm{kg}^{-1}$; em pedras calcárias, de $10-450 \mathrm{mg} \mathrm{kg}^{-1}$; e em estercos, de $15-250 \mathrm{mg} \mathrm{kg}^{-1}$. Pezzarossa et al. (1993), trabalhando com aplicação de fertilizante fosfatado em hortaliças, encontraram aumento nos teores de $\mathrm{Zn}$ com o aumento das quantidades de adubo aplicado.

Os metais pesados também fazem parte dos componentes ativos de vários agrotóxicos, sendo que o uso de sais de $\mathrm{Zn}$, arsenatos de $\mathrm{Cu}$ e de $\mathrm{Pb}$ e compostos metalo-orgânicos têm elevado os níveis de contaminação do solo com esses elementos (Tiller, 1989). As adições antropogênicas de $\mathrm{Cu}$ em solos iniciaram-se em 1917, com o uso da calda bordalesa (Baker, 1990). Frank et al. (1976) avaliaram a contaminação com metais pesados em 296 campos agrícolas que utilizaram agrotóxicos, e encontraram aumentos nos teores de $\mathrm{Pb}, \mathrm{As}, \mathrm{Cu}$ e $\mathrm{Zn}$. Alguns pesticidas, segundo Kiekens (1990), contêm Zn em concentrações de até $25 \%$, e podem aumentar as concentrações desse elemento no solo.

Portanto, o acúmulo dos metais pesados nos solos agrícolas é freqüentemente causado pelo uso repetido e excessivo de fertilizantes, pesticidas e resíduos orgânicos (Kabata-Pendias \& Pendias, 1984; Alloway, 1990b; Blume \& Brümmer, 1991; GimenoGarcía et al., 1996).

O município de Paty do Alferes, localizado na região serrana do Estado do Rio de Janeiro, tem a agricultura como atividade econômica exclusiva. Lá, são produzidos cerca de $40 \%$ de todo o tomate do Estado do Rio de Janeiro e um porcentual considerável de outras hortaliças, tais como repolho, pepino, vagem, pimentão. Localizada na Mata Atlântica e com áreas de declividade de até 50\%, Paty do Alferes tem uma tradição agrícola de mais de 200 anos, tendo passado pela exploração extrativista de madeira, cultura da cana-de-açúcar, do café, de pecuária leiteira e, nos últimos anos, pela olericultura, com destaque para o tomate estaqueado para consumo in natura. Entretanto, nos últimos anos, apesar dos altos investimentos, a produção agrícola vem decrescendo devido: ao desmatamento ocorrido no decorrer dos anos; à utilização de práticas não adequadas às condições edafoclimáticas; à realização de $90 \%$ das atividades agrícolas em encostas com declividade média de $25 \%$, e com preparo do solo feito morro abaixo sem utilização de práticas conservacionistas, e ao uso abusivo e indiscriminado de agroquímicos (fertilizantes, inseticidas, fungicidas, corretivos de solo e outros), que concorreu para o desequilíbrio do ecossistema, aumentando assim a incidência de pragas e doenças.

Outra característica importante do cultivo de hortaliças nessa região é que, em função do declínio rápido da produtividade, as áreas são abandonadas, dando lugar à pastagem com pouco manejo. $\mathrm{O}$ ciclo médio do tomateiro, principal cultura da região, gira em torno de 3 a 4 anos.

Este trabalho teve o objetivo de avaliar a contaminação do solo, água, sedimentos e hortaliças por metais pesados na microbacia de Caetés e a influência da topografia e do uso agrícola no acúmulo de metais pesados.

\section{MATERIAL E MÉTODOS}

Foram selecionadas, para avaliar a contaminação do solo por metais pesados, provenientes do uso intensivo de agroquímicos, duas toposseqüências, na microbacia de Caetés, no município de Paty do Alferes, RJ. Essa microbacia está a uma altitude média de $650 \mathrm{~m}$ e apresenta relevo muito movimentado, com declividade variando entre $15 \%$ e $50 \%$, e vale do tipo ravina, com fundo estreito, escavado pelas águas pluviais.

Os solos da microbacia apresentam-se intensamente utilizados e pertencem às classes: Latossolos, Podzólicos e Cambissolos. Na região, esses solos mostram características químicas e mineralógicas muito semelhantes, diferenciando-se principalmente pelas características físicas e morfológicas. Apresentam mineralogia caulinítica, sendo o argilomineral revestido por óxidos de $\mathrm{Fe}$ de natureza goethítica, evidenciada pelas cores amarelada e alaranjada (Fernandes, 1998) 
A toposseqüência 1 apresenta menor declividade (25\%) e pendente longa, sendo ocupada de três formas distintas: capoeira, localizada na parte superior; pastagem (antiga área de olericultura), situado na parte inferior plana, e olericultura atual, localizada no meio da área, na parte mais declivosa. A toposseqüência 2 apresenta declividade acentuada $(45 \%)$ e pendente curta, sendo ocupada também daquelas três formas distintas, sendo que a capoeira encontra-se na parte de maior declive; a área de olericultura situa-se na região superior plana, e a pastagem, na parte inferior, de baixa declividade da toposseqüência 2 . As características químicas e físicas dos solos dessas áreas encontram-se na Tabela 1 .

Cada área foi subdividida em três subáreas, coletandose 30 amostras simples por subárea para compor uma amostra composta, constituindo três repetições. Em cada ponto foram coletadas amostras de terra nas seguintes profundidades: 0-5; 5-10; 10-15 e 15-20 cm. Após secagem ao ar, as amostras foram destorroadas e moídas em almofariz de ágata.

Para verificar a biodisponibilidade dos metais pesados nas amostras de terra, procedeu-se à extração seqüencial, determinando-se $\mathrm{Cd}, \mathrm{Co}, \mathrm{Cu}, \mathrm{Ni}, \mathrm{Mn}, \mathrm{Pb}$ e $\mathrm{Zn}$ nas frações hidrossolúvel, trocável, ligada a óxidos de Mn, ligada a óxidos de Fe, orgânica e residual, seguindo metodologia desenvolvida por Keller \& Védy (1994). Para a obtenção dos teores totais desses metais, $1,0 \mathrm{~g}$ de terra foi digerida em blocos de digestão, por duas horas, com água régia.

Para avaliação dos teores de metais pesados nos sedimentos do fundo do córrego principal, que drena a microbacia de Caetés, foram coletadas amostras à montante e à jusante da área agrícola atual da toposseqüência 2 , identificadas como córrego 1 e córrego 2 , respectivamen- te, e no açude, onde desemboca esse córrego. Foram retiradas 30 subamostras para compor cada amostra composta, em três repetições. As amostras de sedimentos foram submetidas à extração seqüencial, utilizando-se a mesma metodologia empregada para as amostras de terra.

Próximos aos pontos onde foram coletados os sedimentos, retiraram-se amostras de água, que constaram de 10 subalíquotas para compor uma amostra composta de um litro, que foi preservado adicionando-se $5,0 \mathrm{~mL}$ de $\mathrm{HNO}_{3}(65 \%)$ (Fundação Estadual de Engenharia do Meio Ambiente, 1979). Para análise dos teores totais de metais pesados, $25 \mathrm{~mL}$ de água de cada amostra foram centrifugados a $10.000 \mathrm{rpm}$ por 20 minutos, para separação das partículas em suspensão.

Também foram coletadas amostras de frutos de tomate (Lycopersicum esculentum L.), pimentão (Capsicum annuum L.), repolho (Brassica oleracea L.) e pepino (Cucumis sativus L.) para análise dos teores de metais pesados. O material coletado foi secado em estufa a $65^{\circ} \mathrm{C}$ até peso constante, e, posteriormente, moído e submetido à digestão nitroperclórica (Embrapa, 1979).

Os teores $\mathrm{Cd}, \mathrm{Co}, \mathrm{Cu}, \mathrm{Mn}, \mathrm{Ni}, \mathrm{Pb}$ e $\mathrm{Zn}$ nos extratos de solo, sedimentos, plantas, e nas amostras de água, foram lidos por espectrofotometria de absorção atômica, empregando-se chama ar-acetileno, com os seguintes limites de detecção (mg L$\left.{ }^{-1}\right)$ : Cd: 0,0022; Ni: 0,0700; Pb: 0,0150; Zn: 0,0012; Cu: 0,0045; Mn: 0,0030 e Co: 0,0075.

O delineamento estatístico utilizado no trabalho foi o de blocos casualizados, com parcelas subdivididas, sendo o meio de ocupação da área a parcela, e as profundidades de amostragem, as subparcelas. Os resultados foram analisados utilizando-se análise de variância, e o teste de Tukey a 5\% de probabilidade, para comparação das médias. Rela-

TABELA 1. Características químicas e físicas das amostras de solo, na profundidade de 0-20 cm, das áreas de capoeira, olericultura atual e pastagem (antiga olericultura) de duas toposseqüências da microbacia de Caetés, Paty do Alferes, RJ.

\begin{tabular}{|c|c|c|c|c|c|c|c|c|c|c|c|c|}
\hline \multirow[t]{2}{*}{ Local } & $\mathrm{pH}$ & $\mathrm{K}$ & $\mathrm{Ca}$ & $\mathrm{Mg}$ & $\mathrm{Al}$ & $\mathrm{H}^{1}$ & $\mathrm{Na}$ & CTC & $\mathrm{C}$ & Areia & Silte & Argila \\
\hline & & \multicolumn{7}{|c|}{ 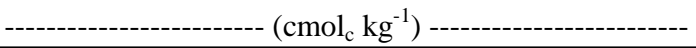 } & \multicolumn{4}{|c|}{----------------- (\%) --------------. } \\
\hline & \multicolumn{12}{|c|}{ Toposseqüência 1} \\
\hline Capoeira & 5,3 & 0,25 & 1,0 & 2,1 & 0,35 & 17,4 & 0,08 & 21,18 & 1,67 & 48 & 9 & 43 \\
\hline Ol. atual & 5,6 & 0,91 & 2,8 & 2,0 & 0,15 & 6,3 & 0,15 & 12,31 & 1,13 & 59 & 6 & 35 \\
\hline \multirow[t]{2}{*}{ Pastagem } & 5,6 & 0,20 & 3,0 & 3,1 & 0,00 & 2,6 & 0,09 & 8,99 & 1,02 & 66 & 9 & 25 \\
\hline & \multicolumn{12}{|c|}{ Toposseqüência 2} \\
\hline Capoeira & 4,7 & 0,16 & 1,7 & 2,5 & 0,20 & 17,5 & 0,07 & 22,13 & 1,75 & 63 & 7 & 30 \\
\hline Ol. atual & 4,7 & 0,06 & 1,0 & 1,0 & 0,90 & 9,9 & 0,04 & 12,00 & 1,10 & 47 & 15 & 38 \\
\hline Pastagem & 5,5 & 0,22 & 3,0 & 3,1 & 0,00 & 6,3 & 0,09 & 12,71 & 1,18 & 53 & 16 & 31 \\
\hline
\end{tabular}

${ }^{1}$ Acetato de cálcio, $\mathrm{pH} 7,0$. 
tivas ao mesmo metal, foram comparadas as médias nas profundidades dentro de cada ocupação da área. Foram comparadas as médias dentro de cada metal, entre as diferentes ocupações da mesma toposseqüência.

Na Tabela 2 são apresentados os principais agrotóxicos, por nome técnico, utilizados no município de Paty do Alferes, segundo IBGE (1995).

\section{RESULTADOS E DISCUSSÃO}

Na Tabela 3 pode-se observar que os teores de $\mathrm{Zn}, \mathrm{Pb}, \mathrm{Ni}, \mathrm{Mn}, \mathrm{Cu}$ e Co são significativamente mais elevados nas áreas de pasto (anteriormente áreas de olericultura), em comparação com as áreas não cultivadas de capoeira. Essas áreas de pasto receberam, durante vários anos (ciclo médio de quatro anos), aplicações de agrotóxicos e fertilizantes, contendo principalmente $\mathrm{Zn}$, $\mathrm{Cu}$ e $\mathrm{Mn}$, metais que tiveram os maiores incrementos (Tabela 3). As áreas de olericultura atual, com exploração recente, não apresentaram teores de metais pesados elevados em relação à área de capoeira. Na toposseqüência 1, os valores de metais pesados foram inferiores aos da área com capoeira, provavelmente devido ao carreamento e acúmulo desses elementos para a área de pasto que fica na parte baixa da topossequiência 1 , e que apresenta os maiores valores de metais pesa- dos. Segundo Alloway (1990b), os fertilizantes, os fungicidas, os inseticidas e os herbicidas contêm várias combinações de metais pesados, tanto como constituintes ativos quanto como impurezas.

Os níveis de $\mathrm{Cu}$ são afetados no solo e nas plantas, segundo Frank et al. (1976), Tiller (1989) e Baker (1990), por tratamentos que incluem fungicidas, fertilizantes, estercos de animais, resíduos urbanos e industriais, como no caso deste trabalho. Os resultados obtidos do $\mathrm{Zn}$ também encontram respaldo nos resultados obtidos por Frank et al. (1976), Kiekens (1990), Pezzarossa et al. (1993) e Gimeno-García et al. (1996) nas áreas mais intensamente utilizadas, semelhantes às de pasto, antiga olericultura, nas duas toposseqüências avaliadas.

Os teores mais elevados de metais pesados nas áreas de antiga olericultura não atingiram, exceto para $\mathrm{Zn}$, valores acima dos considerados críticos no solo, de acordo com Kabata-Pendias \& Pendias (1984) e Alloway (1990a).

Verifica-se a tendência da toposseqüência 1, de menor declividade (25\%), de apresentar, na área de pasto (antiga área de olericultura), teores de metais pesados bem mais elevados. Tal observação devese, talvez, ao menor grau de erodibilidade da toposseqüência 1 em relação à toposseqüência 2 . Em decorrência da alta interação dos metais pesados com

TABELA 2. Distribuição de agrotóxicos, por nome técnico, utilizados em Paty do Alferes, RJ'

\begin{tabular}{|c|c|c|c|c|}
\hline Nome técnico & $\begin{array}{l}\text { Quantidade do } \\
\text { princípio ativo }\end{array}$ & Quantidade total & Área & Quantidade/área \\
\hline & $(\mathrm{kg})$ & $(\%)$ & (ha) & $\left(\mathrm{kg} \mathrm{ha}^{-1}\right)$ \\
\hline Mancozeb & 2182,16 & 30,91 & 72,93 & 29,18 \\
\hline Malathion & 1211,40 & 17,59 & 49,46 & 24,49 \\
\hline Methamidophos & 1062,66 & 15,43 & 106,69 & 9,96 \\
\hline Óxido cuproso & 845,24 & 12,28 & 123,55 & 6,84 \\
\hline Oxicloreto de cobre & 239,04 & 3,47 & 10,68 & 22,38 \\
\hline Permethrin & 228,90 & 3,32 & 97,04 & 2,36 \\
\hline Cartap & 227,44 & 3,30 & 97,72 & 2,33 \\
\hline Enxofre & 220,16 & 3,20 & 40,46 & 5,44 \\
\hline Vamidothion & 143,70 & 2,09 & 33,04 & 4,35 \\
\hline Thiophanate methyl + chlorotalonil & 86,10 & 1,25 & 8,64 & 9,97 \\
\hline Mancozeb + thiophanate & 78,00 & 1,13 & 10,50 & 7,43 \\
\hline Maneb + zineb & 65,00 & 0,94 & 8,00 & 8,13 \\
\hline Chlorotalonil & 61,50 & 0,89 & 14,60 & 4,21 \\
\hline Thiophanate methyl & 54,13 & 0,79 & 18,08 & 2,99 \\
\hline
\end{tabular}

${ }^{1}$ IBGE (1995). 
TABela 3. Teores totais de $\mathrm{Zn}, \mathrm{Pb}, \mathrm{Ni}, \mathrm{Mn}, \mathrm{Cu}, \mathrm{Cd}$ e Co, em amostras de solo de diferentes áreas de duas toposseqüências da microbacia de Caetés, Paty do Alferes, RJ1. Média de três repetições.

\begin{tabular}{|c|c|c|c|c|c|c|c|c|}
\hline Área & $\begin{array}{l}\text { Prof. } \\
(\mathrm{cm})\end{array}$ & \multicolumn{7}{|c|}{ - } \\
\hline & & & & Toposs & jüência 1 & & & \\
\hline \multirow{4}{*}{ Capoeira } & $0-5$ & $36,39 \mathrm{bB}$ & $25,31 \mathrm{aB}$ & $9,06 \mathrm{cB}$ & $64,06 \mathrm{aC}$ & $16,80 \mathrm{aC}$ & $0,70 \mathrm{aAB}$ & $4,17 \mathrm{aB}$ \\
\hline & $5-10$ & $31,81 \mathrm{bcB}$ & $25,31 \mathrm{aB}$ & $9,23 \mathrm{cB}$ & $51,12 \mathrm{bC}$ & $16,48 \mathrm{aB}$ & $0,77 \mathrm{aA}$ & 4,16aB \\
\hline & $10-15$ & $29,51 \mathrm{cB}$ & $25,95 \mathrm{aB}$ & $9,98 \mathrm{aB}$ & $38,63 \mathrm{cB}$ & $14,83 \mathrm{bC}$ & $0,77 \mathrm{aB}$ & $4,18 \mathrm{aB}$ \\
\hline & $15-20$ & $38,24 \mathrm{aB}$ & $26,24 \mathrm{aB}$ & $9,79 \mathrm{bB}$ & $20,96 \mathrm{dC}$ & $14,63 \mathrm{bC}$ & $0,80 \mathrm{bB}$ & $3,67 \mathrm{bB}$ \\
\hline \multirow[t]{4}{*}{ Olericultura atual } & $0-5$ & $21,07 \mathrm{aC}$ & $23,29 \mathrm{aC}$ & $7,09 \mathrm{cC}$ & $29,10 \mathrm{aB}$ & $26,41 \mathrm{aA}$ & $0,64 \mathrm{aB}$ & $2,78 \mathrm{aC}$ \\
\hline & $5-10$ & $21,4 \mathrm{aC}$ & $23,86 \mathrm{aB}$ & $7,07 \mathrm{cC}$ & $28,52 \mathrm{aB}$ & $24,30 \mathrm{bA}$ & $0,69 \mathrm{aA}$ & $2,79 \mathrm{aC}$ \\
\hline & $10-15$ & $21,59 \mathrm{aC}$ & $22,39 \mathrm{aC}$ & $7,80 \mathrm{bC}$ & $31,08 \mathrm{aC}$ & $24,36 \mathrm{bA}$ & $0,70 \mathrm{aA}$ & $2,83 \mathrm{aC}$ \\
\hline & $15-20$ & $21,23 \mathrm{aC}$ & $22,35 \mathrm{aC}$ & $8,02 \mathrm{aC}$ & $29,08 \mathrm{aB}$ & $25,31 \mathrm{abA}$ & $0,63 \mathrm{aA}$ & $2,90 \mathrm{aC}$ \\
\hline \multirow{5}{*}{ Pastagem } & $0-5$ & $109,0 \mathrm{aA}$ & $28,33 \mathrm{bA}$ & $15,87 \mathrm{bA}$ & $291,80 \mathrm{cA}$ & $24,43 \mathrm{aB}$ & $0,80 \mathrm{aA}$ & $6,86 \mathrm{aA}$ \\
\hline & $5-10$ & $106,2 \mathrm{aA}$ & $27,89 \mathrm{bA}$ & $16,33 \mathrm{aA}$ & $312,40 \mathrm{bA}$ & $24,54 \mathrm{aA}$ & $0,77 \mathrm{aA}$ & $6,93 \mathrm{aA}$ \\
\hline & $10-15$ & $105,0 \mathrm{aA}$ & $30,73 \mathrm{aA}$ & $16,38 \mathrm{aA}$ & $337,00 \mathrm{aA}$ & $22,77 \mathrm{bB}$ & $0,73 \mathrm{aA}$ & $6,89 \mathrm{aA}$ \\
\hline & $15-20$ & $70,58 \mathrm{bA}$ & $28,37 \mathrm{bA}$ & $15,79 \mathrm{bA}$ & $264,70 \mathrm{dA}$ & $23,83 \mathrm{abB}$ & $0,77 \mathrm{aA}$ & $6,42 \mathrm{bA}$ \\
\hline & \multicolumn{8}{|c|}{ Toposseqüência 2} \\
\hline \multirow{4}{*}{ Capoeira } & $0-5$ & $53,32 \mathrm{aC}$ & $24,70 \mathrm{cB}$ & $8,19 \mathrm{cB}$ & $78,07 \mathrm{cC}$ & $19,54 \mathrm{bB}$ & $0,53 \mathrm{bB}$ & $3,34 \mathrm{cB}$ \\
\hline & $5-10$ & $55,10 \mathrm{aC}$ & $26,42 \mathrm{bA}$ & $9,01 \mathrm{bC}$ & $79,79 \mathrm{bC}$ & $19,32 \mathrm{bB}$ & $0,57 \mathrm{abA}$ & $4,18 b C$ \\
\hline & $10-15$ & $53,26 \mathrm{aB}$ & $28,77 \mathrm{aA}$ & $11,09 \mathrm{aB}$ & $76,77 \mathrm{cC}$ & $20,55 \mathrm{aB}$ & $0,61 \mathrm{aA}$ & $4,86 \mathrm{aB}$ \\
\hline & $15-20$ & $49,48 \mathrm{bB}$ & $29,74 \mathrm{aA}$ & $11,04 \mathrm{aB}$ & $118,10 \mathrm{aC}$ & $20,82 \mathrm{aB}$ & $0,59 \mathrm{abA}$ & $4,23 b C$ \\
\hline \multirow[t]{4}{*}{ Olericultura atual } & $0-5$ & $58,88 \mathrm{abB}$ & $27,42 \mathrm{aA}$ & $11,11 \mathrm{aA}$ & $183,20 \mathrm{aA}$ & $19,34 \mathrm{aB}$ & $0,61 \mathrm{aA}$ & $4,71 \mathrm{abA}$ \\
\hline & $5-10$ & $58,12 \mathrm{abB}$ & $25,61 \mathrm{bA}$ & $11,28 \mathrm{aB}$ & $135,90 \mathrm{cB}$ & $18,92 \mathrm{aC}$ & $0,62 \mathrm{aA}$ & $4,48 \mathrm{bB}$ \\
\hline & $10-15$ & $56,25 \mathrm{cA}$ & $26,20 \mathrm{abB}$ & $11,41 \mathrm{aB}$ & $136,50 \mathrm{cB}$ & $19,41 \mathrm{aC}$ & $0,62 \mathrm{aA}$ & $4,62 \mathrm{abC}$ \\
\hline & $15-20$ & $60,53 \mathrm{aA}$ & $26,89 \mathrm{abB}$ & $11,22 \mathrm{aB}$ & $148,60 \mathrm{bB}$ & $19,26 \mathrm{aC}$ & $0,58 \mathrm{aA}$ & $4,75 \mathrm{aB}$ \\
\hline \multirow[t]{4}{*}{ Pastagem } & $0-5$ & $66,13 \mathrm{aA}$ & $20,62 \mathrm{aC}$ & $11,11 \mathrm{cA}$ & $147,60 \mathrm{bB}$ & $30,01 \mathrm{aA}$ & $0,55 \mathrm{aB}$ & $4,75 \mathrm{bA}$ \\
\hline & $5-10$ & $61,31 \mathrm{bA}$ & $20,22 \mathrm{abB}$ & $12,12 \mathrm{bA}$ & $178,20 \mathrm{aA}$ & $26,63 \mathrm{cA}$ & $0,53 \mathrm{aB}$ & $4,81 \mathrm{bA}$ \\
\hline & $10-15$ & $56,87 \mathrm{cA}$ & $18,73 b C$ & $12,98 \mathrm{aA}$ & $178,60 \mathrm{aA}$ & $26,53 \mathrm{cA}$ & $0,56 \mathrm{aA}$ & $5,37 \mathrm{aA}$ \\
\hline & $15-20$ & $50,18 \mathrm{~dB}$ & $18,34 \mathrm{cC}$ & $12,96 \mathrm{aA}$ & $181,50 \mathrm{aA}$ & $29,00 \mathrm{bA}$ & $0,53 \mathrm{aB}$ & $5,40 \mathrm{aA}$ \\
\hline
\end{tabular}

${ }^{1}$ Letras minúsculas comparam médias, entre profundidades, do mesmo metal e mesma ocupação na mesma toposseqüência; letras maiúsculas comparam médias do mesmo metal entre ocupações na mesma toposseqüência; médias com letras iguais não diferem estatisticamente entre si a 5\% de probabilidade, pelo teste de Tukey.

grupos funcionais inorgânicos (hidroxila) e orgânicos (carboxila) dos solos intemperizados, estes, geralmente, se acumulam superficialmente nos solos contaminados (Sposito, 1989). Como a toposseqüência 2 apresenta maior declividade (45\%), as perdas da camada superficial do solo são mais intensas, acentuando o empobrecimento de metais pesados na profundidade de $0-20 \mathrm{~cm}$. Na toposseqüência 1, os maiores teores dos metais pesados, com exceção do $\mathrm{Ni}$, foram encontrados na camada de $0-10 \mathrm{~cm}$

A distribuição porcentual dos metais pesados extraídos seqüencialmente encontra-se nas Figs. 1, $2,3,4,5$ e 6 . Pode-se observar que o Mn foi o único elemento que, em todas as áreas, apresentou porcentual do total de até $15 \%$, distribuído na fração trocável, a biodisponível. O teor de metais pesados das frações hidrossolúvel e trocável é um indicador da quantidade de metais disponíveis para as plantas (He \& Singh, 1993). Gimeno-García et al. (1996), trabalhando com fertilizantes e agrotóxicos, também verificaram que o $\mathrm{Mn}$ foi o elemento mais biodisponível nos solos analisados, a exemplo deste trabalho. A proporção dessas frações em relação ao conteúdo total do metal é um indicador da sua mobilidade. Contrastando com o comportamento do $\mathrm{Mn}$, o Cd e o Ni apresentam $100 \%$ e $80 \%$ da sua distribuição porcentual na fração residual, respectivamente. $\mathrm{O} \mathrm{Pb}$ e o Co tiveram sua distribuição concentrada nas frações residual e ligadas a óxidos de Fe e Mn. 


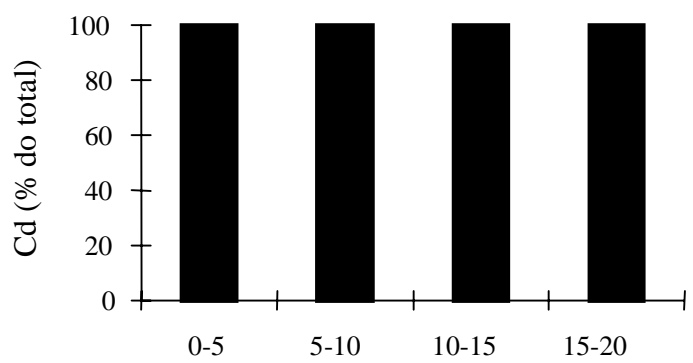

Profundidade $(\mathrm{cm})$

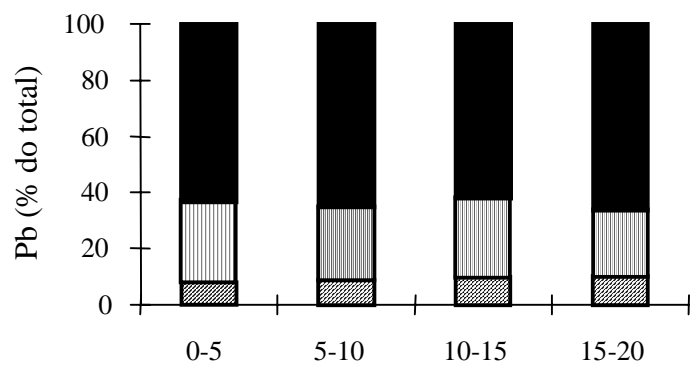

Profundidade $(\mathrm{cm})$
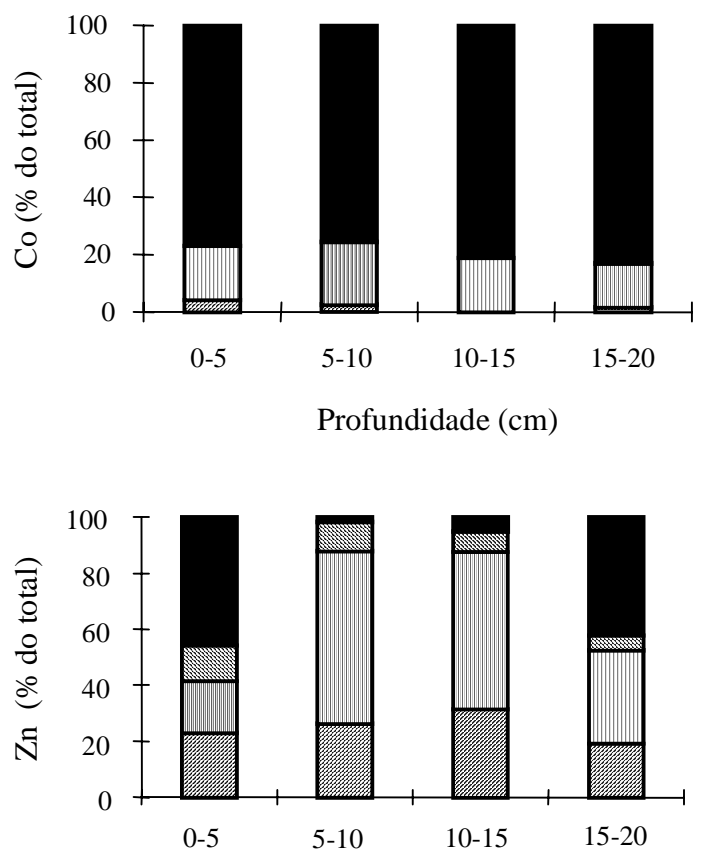

Profundidade $(\mathrm{cm})$
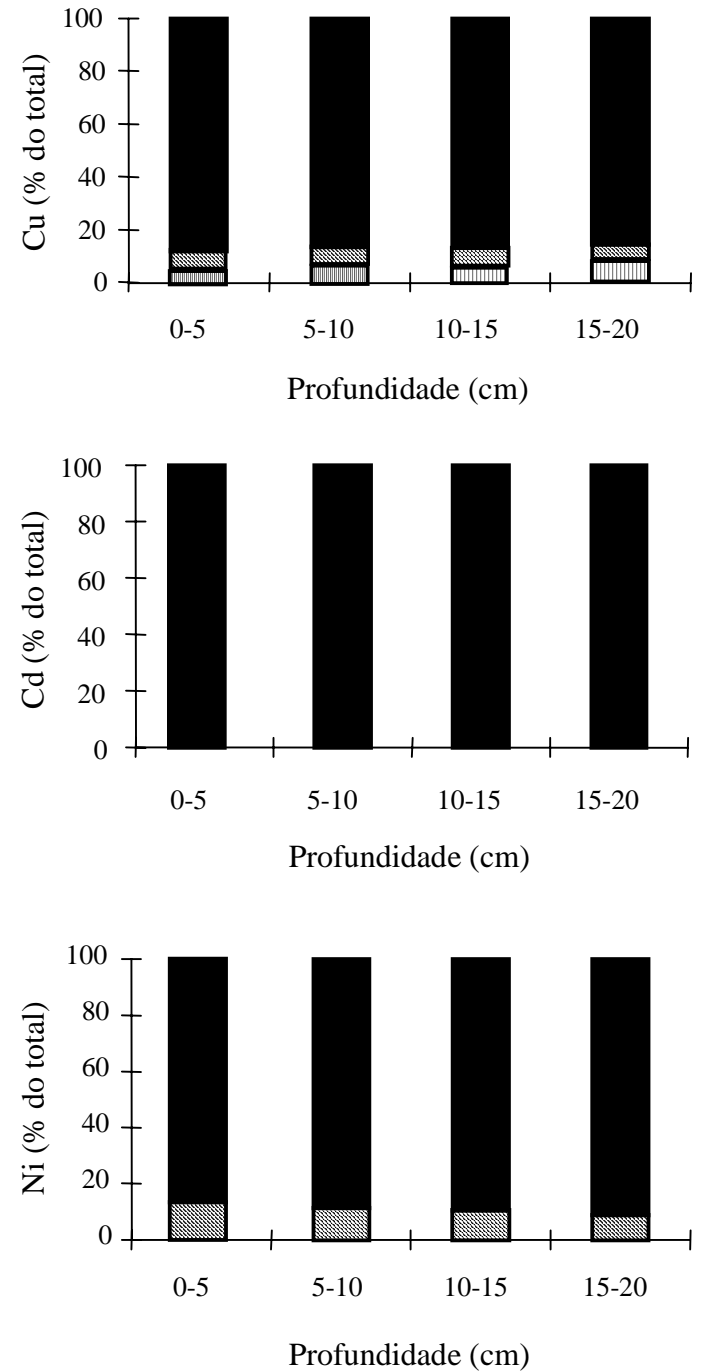

Profundidade $(\mathrm{cm})$

FIG. 1. Distribuição porcentual de $\mathrm{Cd}, \mathrm{Co}, \mathrm{Cu}, \mathrm{Ni}, \mathrm{Mn}, \mathrm{Pb}$ e $\mathrm{Zn}$ nas frações do solo da área de capoeira da topossequiência 1 da microbacia de Caetés, Paty do Alferes, RJ. 

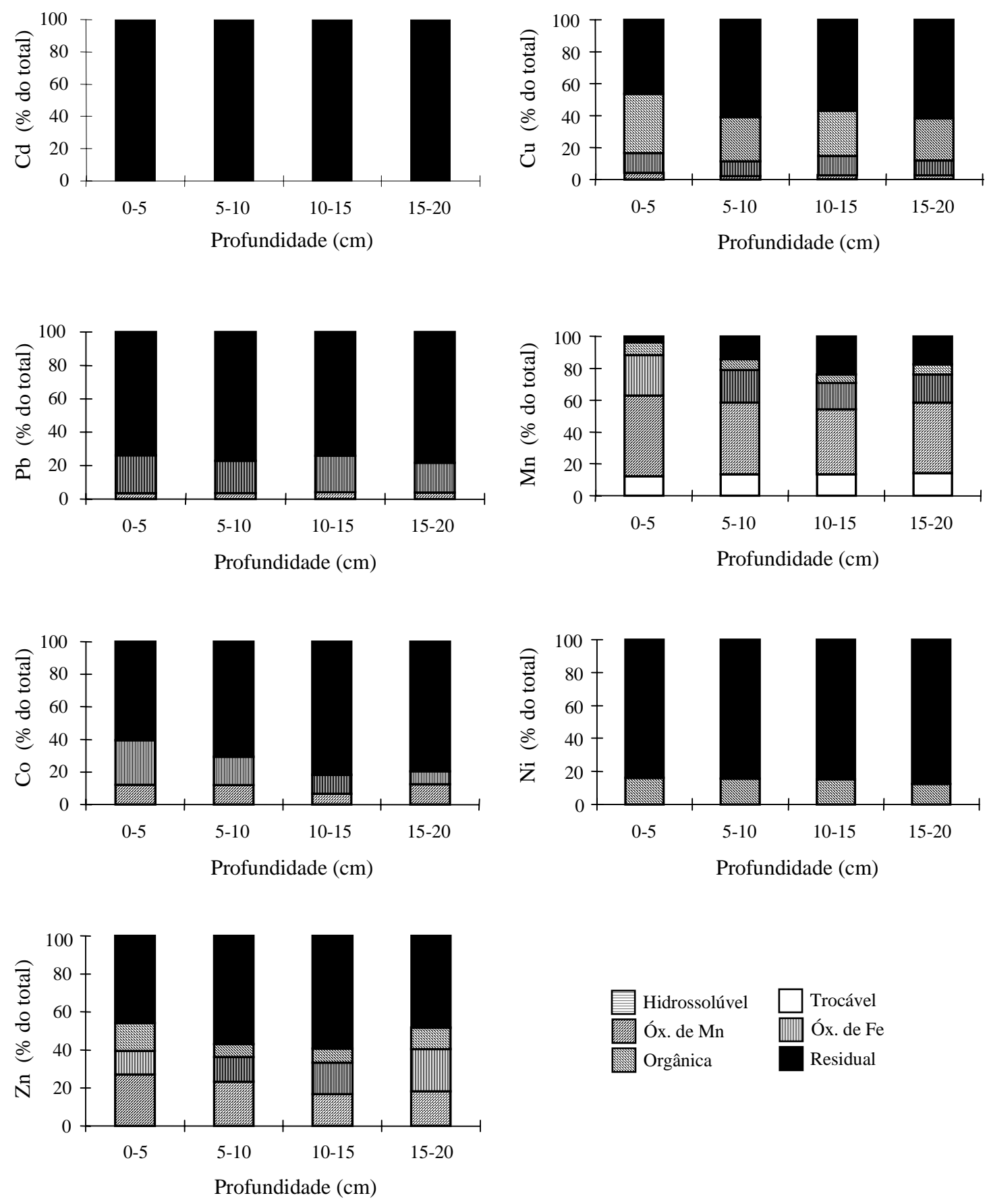

FIG. 2. Distribuição porcentual de $\mathrm{Cd}, \mathrm{Co}, \mathrm{Cu}, \mathrm{Ni}, \mathrm{Mn}, \mathrm{Pb}$ e $\mathrm{Zn}$ nas frações do solo da área de olericultura atual da toposseqüência 1 da microbacia de Caetés, Paty do Alferes, RJ. 

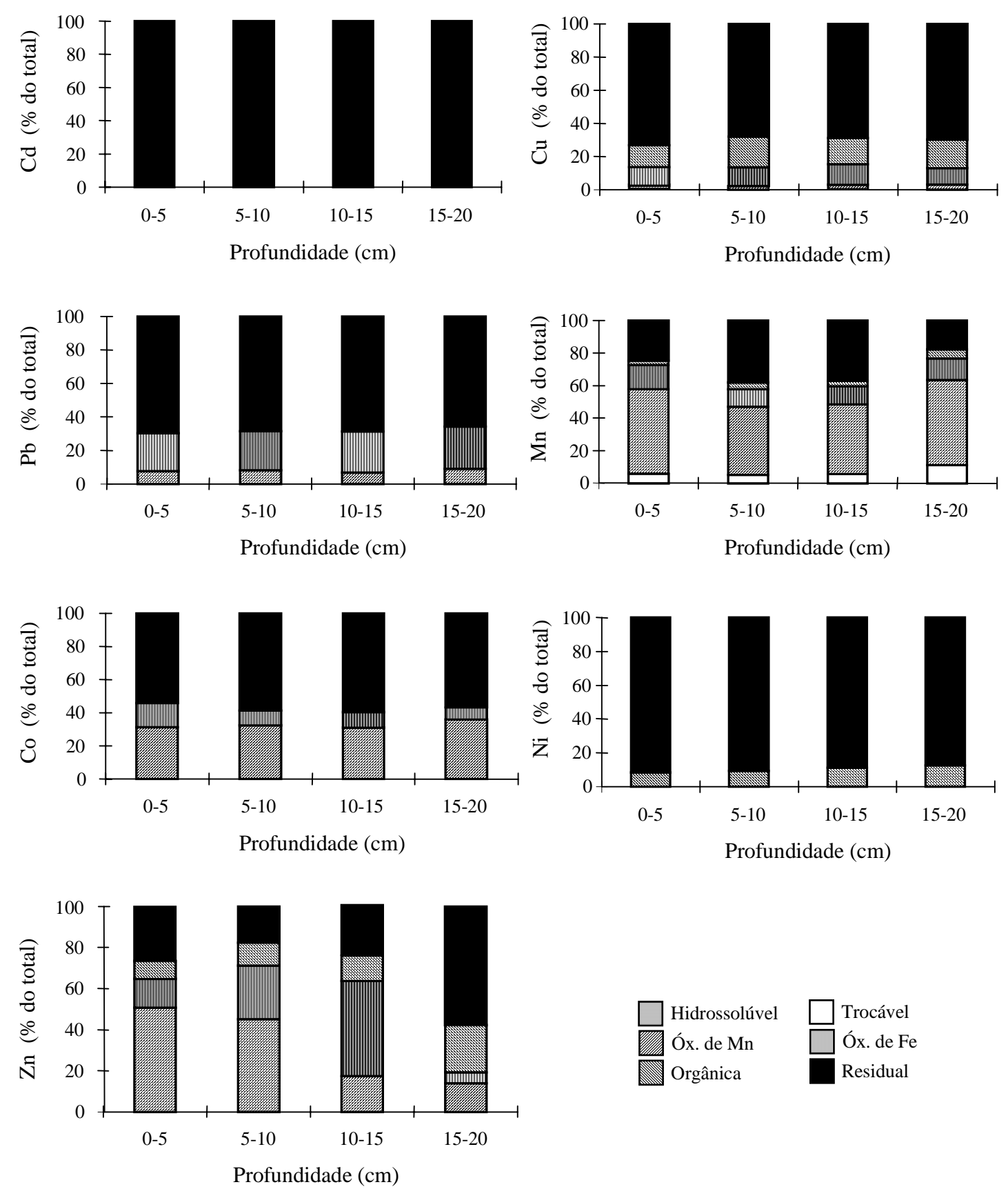

FIG. 3. Distribuição porcentual de $\mathrm{Cd}, \mathrm{Co}, \mathrm{Cu}, \mathrm{Ni}, \mathrm{Mn}, \mathrm{Pb}$ e $\mathrm{Zn}$ nas frações do solo da área de pastagem (antiga olericultura) da toposseqüência 1 da microbacia de Caetés, Paty do Alferes, RJ.

$\mathrm{O} \mathrm{Zn}$ se distribuiu em todas as frações não biodisponíveis do solo, com altos porcentuais nas frações ligadas aos óxidos.
Tais resultados mostram que, nessas áreas, os metais pesados estão na sua maior parte imobilizados no solo, com baixa disponibilidade para as plan- 

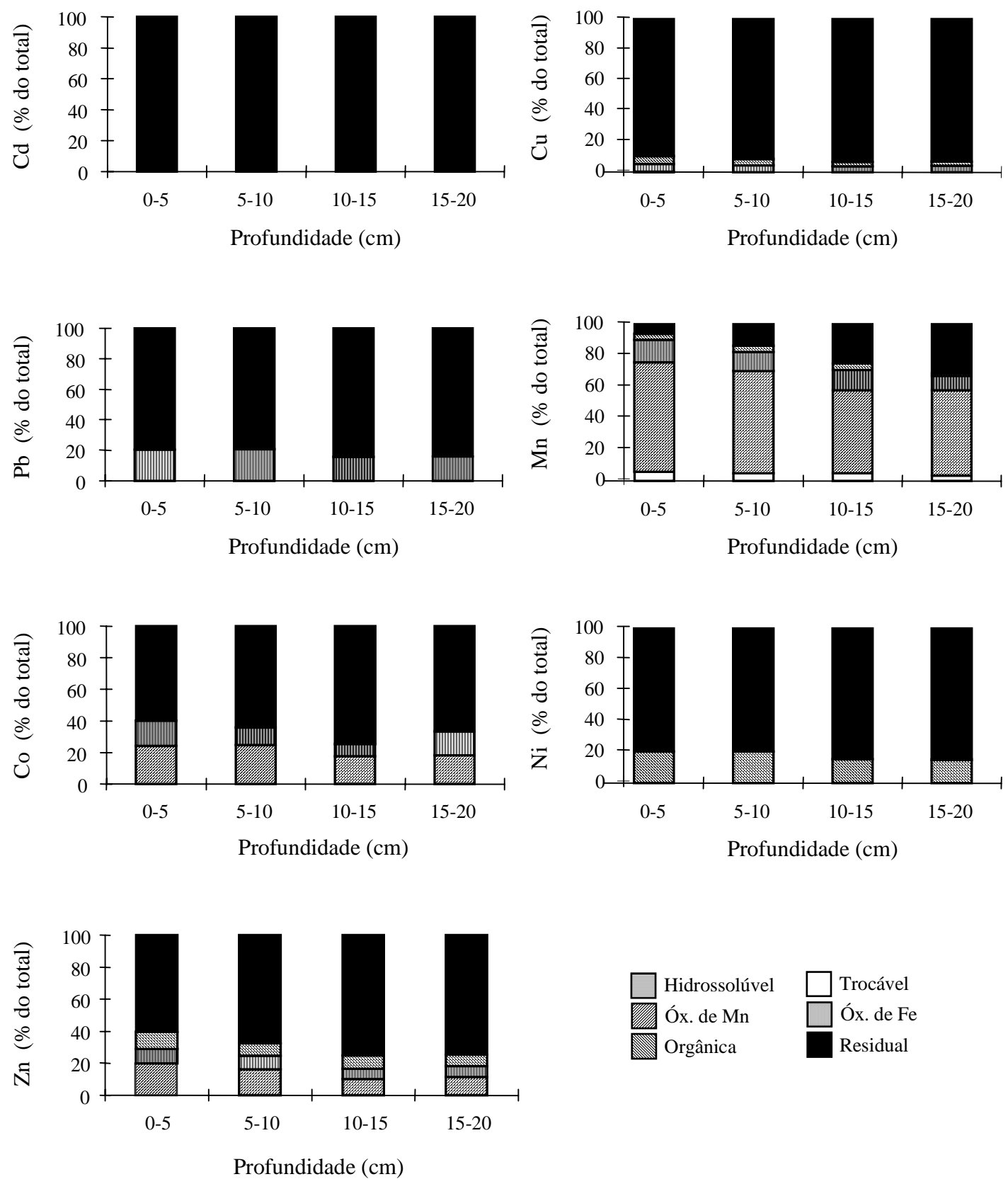

FIG. 4. Distribuição porcentual de $\mathrm{Cd}, \mathrm{Co}, \mathrm{Cu}, \mathrm{Ni}, \mathrm{Mn}, \mathrm{Pb}$ e $\mathrm{Zn}$ nas frações do solo da área de capoeira da toposseqüência 2 da microbacia de Caetés, Paty do Alferes, RJ.

tas e pequenos riscos de contaminação do lençol freático. Resultados semelhantes foram obtidos por Pezzarossa et al. (1993), que observaram aumentos significativos dos teores totais de $\mathrm{Zn}$ (de 60,9 para 71,3 $\mathrm{mg} \mathrm{kg}^{-1}$ ) e $\mathrm{Cu}$ (de 57,3 para 73,9 $\mathrm{mg} \mathrm{kg}^{-1}$ ) no solo cultivado com tomateiro após aplicações de fertili- 

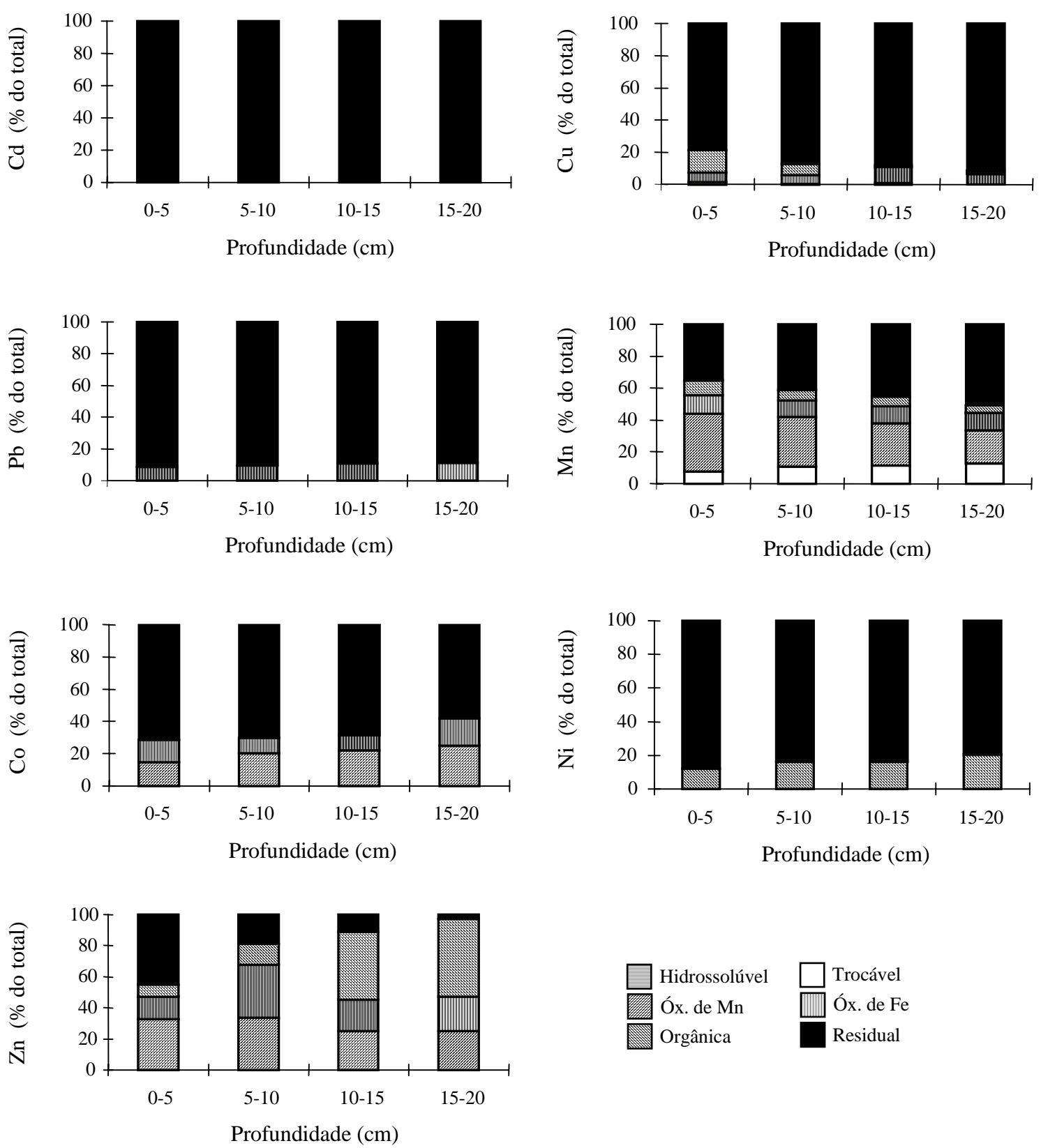

FIG. 5. Distribuição porcentual de $\mathrm{Cd}, \mathrm{Co}, \mathrm{Cu}, \mathrm{Ni}, \mathrm{Mn}, \mathrm{Pb}$ e $\mathrm{Zn}$ nas frações do solo da área de olericultura atual da toposseqüiência 2 da microbacia de Caetés, Paty do Alferes, RJ.

zantes fosfatados. Entretanto, não encontraram concentrações diferentes de metais pesados nas frações biodisponíveis entre as diferentes doses de $\mathrm{P}$ devido, principalmente, à imobilização no solo, pela for- mação de hidróxidos insolúveis.

Esses dados corroboram as afirmações de Cañadas et al. (1986), Xian (1987) e Petruzzelli et al. (1989), de que os elementos de baixa mobilidade e 

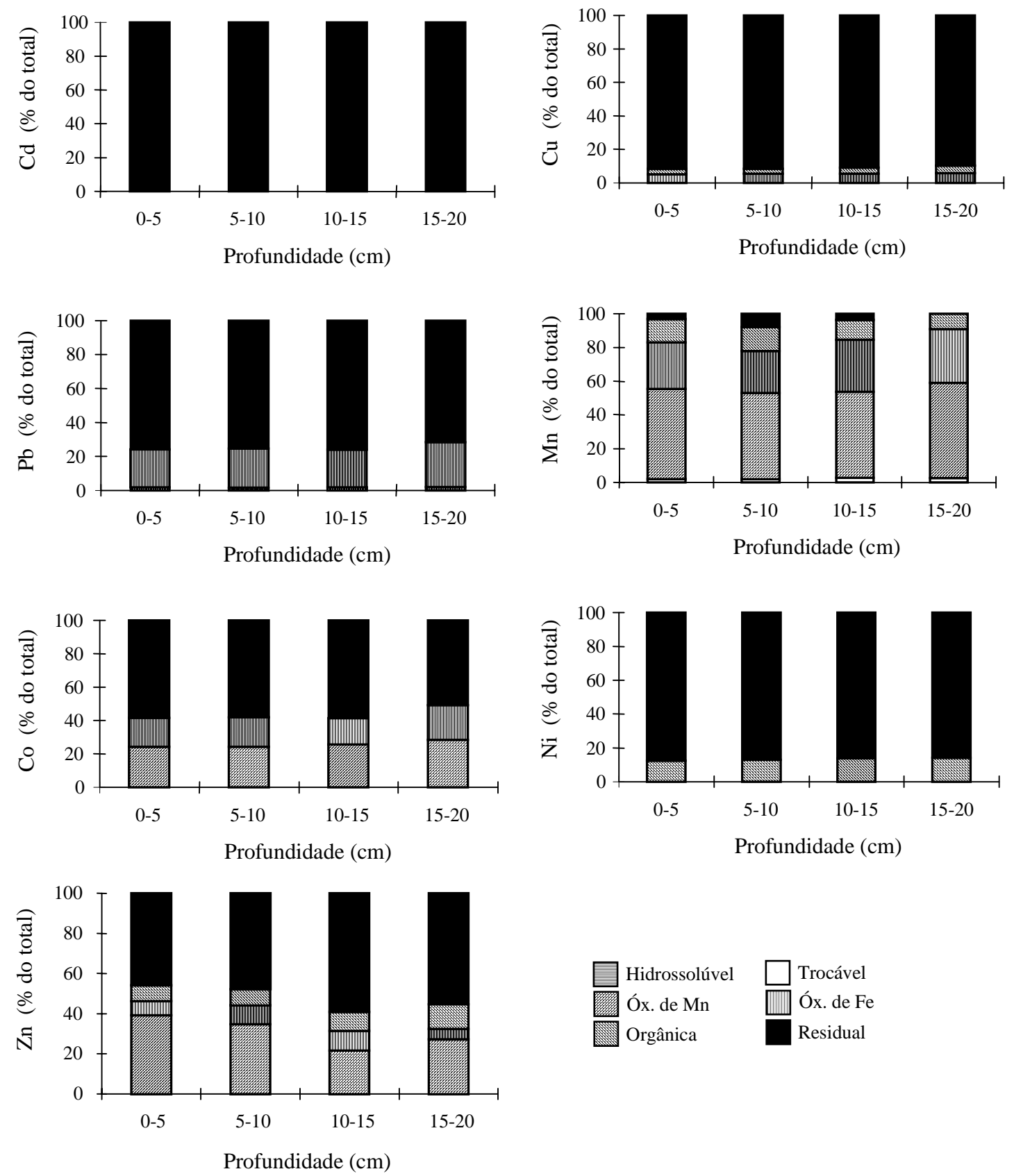

FIG. 6. Distribuição porcentual de $\mathrm{Cd}, \mathrm{Co}, \mathrm{Cu}, \mathrm{Ni}, \mathrm{Mn}, \mathrm{Pb}$ e $\mathrm{Zn}$ nas frações do solo da área de pastagem (antiga olericultura) atual da toposseqüência 2 da microbacia de Caetés, Paty do Alferes, RJ.

disponibilidade estão retidos nas frações ligadas a óxidos de Fe e Mn, orgânica e residual. Para Blume \& Brümmer (1991), os grupos funcionais de substânci- as húmicas, óxidos de $\mathrm{Fe}, \mathrm{Mn}$ e $\mathrm{Al}$, e minerais de argila (caulinita), são os constituintes que, predominantemente, se ligam aos metais no solo, levando à 
formação de complexos estáveis (inner sphere) e, por conseguinte, sua imobilização, tornando esses elementos pouco disponíveis para absorção pelas plantas.

Os resultados obtidos nas análises de amostras de tomateiro, pimentão, repolho e pepino (Tabela 4) mostram que os teores de todos os metais pesados analisados estavam dentro da faixa normal estabelecida, com relação a essas plantas.

Os resultados obtidos no tocante aos teores totais de $\mathrm{Cd}, \mathrm{Co}, \mathrm{Cu}, \mathrm{Mn}, \mathrm{Ni}, \mathrm{Pb}$ e $\mathrm{Zn}$, nas amostras de sedimentos, estão apresentados na Tabela 5. Observa-se, em relação aos sedimentos, que as amostras retiradas no córrego 2, isto é, na posição de maior influência das áreas cultivadas, assim como as amostras coletadas no açude, apresentaram aumentos estatisticamente mais significativos dos teores de todos os metais pesados, em comparação com as amostras retiradas do córrego na posição à montante da área sob olericultura (córrego 1), com destaque para os aumentos nos teores de Zn e Mn (incrementos de quase $200 \%$ ). Esses resultados corroboram as observações feitas anteriormente, isto é, em razão da alta erodibilidade dos solos da microbacia, as partículas de solo contaminadas pelo uso intensivo de agroquímicos foram transportados para o córrego, causando a elevação dos teores de metais pesados nos sedimentos. Tais resultados são ratificados pelos baixos teores desses elementos à montante da área de influência da atividade agrícola.
A análise dos sedimentos tem sido usada, há muito tempo, como indicadora da poluição por metais pesados, em razão da sua habilidade de integrar as descargas liberadas no sistema (Lacerda, 1982; Fiszman et al., 1984; Lacerda et al., 1993; Bubb \& Lester, 1994). A deposição dos metais pesados nos sedimentos dos rios deveria ser observada cuidadosamente num programa de monitoramento, de forma a avaliar sua dispersão, disponibilidade e absorção pela biota (Malm et al.,1989).

Do mesmo modo que nos solos, os metais pesados extraídos seqüencialmente nos sedimentos encontraram-se nas frações residual e orgânica e nas frações ligadas a óxidos de Mn e Fe (Fig. 7). Esses resultados diferem dos obtidos por Malm et al. (1989), referentes a sedimentos do rio Paraíba do Sul, que observaram que o $\mathrm{Cu}, \mathrm{Pb}$, Mn e $\mathrm{Zn}$ estavam ligados, predominantemente, à fração trocável, de alta biodisponibilidade.

Para Bubb \& Lester (1994), a adsorção dos metais pesados pelos sedimentos em suspensão (principalmente óxidos de Fe e Mn, matéria orgânica e argilas) transferem esses elementos da água para os sedimentos, tornando-os pouco biodisponíveis, o que parece ser o caso deste trabalho.

Os teores totais de metais pesados nas amostras de água, apresentados na Tabela 6 , mostram valores significativamente mais elevados de $\mathrm{Zn}, \mathrm{Pb}, \mathrm{Cu}$ e Mn nas amostras do córrego 2 e do açude, tendo um comportamento semelhante ao observado quanto aos

TABELA 4. Teores totais de metais pesados em amostras de tomateiro (Lycopersicum esculentum L.), pimentão (Capsicum annuum L.), repolho (Brassica oleracea L.) e pepino (Cucumis sativus L.), nas áreas sob olericultura atual de duas toposseqüências (T1 e T2) da microbacia de Caetés, Paty do Alferes, RJ. Média de três repetições.

\begin{tabular}{|c|c|c|c|c|c|c|c|}
\hline Cultura & $\mathrm{Zn}$ & $\mathrm{Pb}$ & $\mathrm{Ni}$ & $\mathrm{Mn}$ & $\mathrm{Cu}$ & $\mathrm{Cd}$ & $\mathrm{Co}$ \\
\hline & \multicolumn{7}{|c|}{ 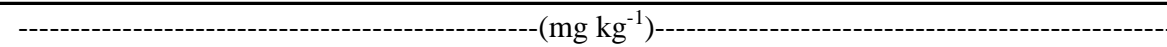 } \\
\hline Tomateiro (T1) & 1,40 & 0,140 & 0,136 & 0,324 & 0,324 & $<0,002$ & $<0,007$ \\
\hline Pepino (T1) & 1,32 & 0,104 & 0,124 & 0,360 & 0,280 & $<0,002$ & $<0,007$ \\
\hline Repolho (T1) & 0,76 & 0,144 & $<0,070$ & 0,768 & 0,116 & $<0,002$ & $<0,007$ \\
\hline Pimentão (T1) & 0,80 & 0,096 & 0,048 & 0,340 & 0,272 & $<0,002$ & $<0,007$ \\
\hline Pimentão (T2) & 0,72 & 0,096 & 0,068 & 0,424 & 0,388 & $<0,002$ & $<0,007$ \\
\hline Faixa normal $^{1}$ & $1-400$ & $0,2-20$ & $0,02-5$ & $20-1000$ & $5-20$ & $0,1-2,4$ & $0,02-1$ \\
\hline Faixa crítica $^{1}$ & $100-400$ & $30-300$ & $10-100$ & $300-500$ & $20-100$ & $5-30$ & $15-50$ \\
\hline
\end{tabular}

${ }^{1}$ Segundo Alloway (1990a). 
TABela 5. Teores totais de $\mathrm{Zn}, \mathrm{Cd}, \mathrm{Ni}, \mathrm{Pb}, \mathrm{Co}, \mathrm{Cu}$ e $\mathrm{Mn}$, em amostras de sedimentos da microbacia de Caetés, Paty do Alferes, $\mathbf{R J}^{1}$. Média de três repetições.

\begin{tabular}{|c|c|c|c|c|c|c|c|}
\hline Local & $\mathrm{Zn}$ & $\mathrm{Cd}$ & $\mathrm{Ni}$ & $\mathrm{Pb}$ & Co & $\mathrm{Cu}$ & $\mathrm{Mn}$ \\
\hline & \multicolumn{7}{|c|}{ 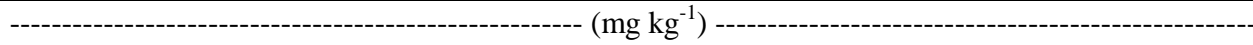 } \\
\hline Córrego 1 & $25,90 \mathrm{C}$ & $0,26 \mathrm{C}$ & $7,33 \mathrm{C}$ & $13,92 \mathrm{~B}$ & $0,93 \mathrm{C}$ & $14,96 \mathrm{C}$ & $29,68 \mathrm{C}$ \\
\hline Córrego 2 & $449,40 \mathrm{~A}$ & $0,62 \mathrm{~B}$ & 14,38B & $29,42 \mathrm{~A}$ & $2,28 \mathrm{~B}$ & $31,67 \mathrm{~A}$ & $360,50 \mathrm{~A}$ \\
\hline Açude & $66,42 \mathrm{~B}$ & $0,82 \mathrm{~A}$ & $15,37 \mathrm{~A}$ & $29,02 \mathrm{~A}$ & $3,32 \mathrm{~A}$ & $25,36 \mathrm{~B}$ & $116,10 \mathrm{~B}$ \\
\hline
\end{tabular}

${ }^{1}$ Médias com mesma letra não diferem estatisticamente entre si a $5 \%$ de probabilidade, pelo teste de Tukey.
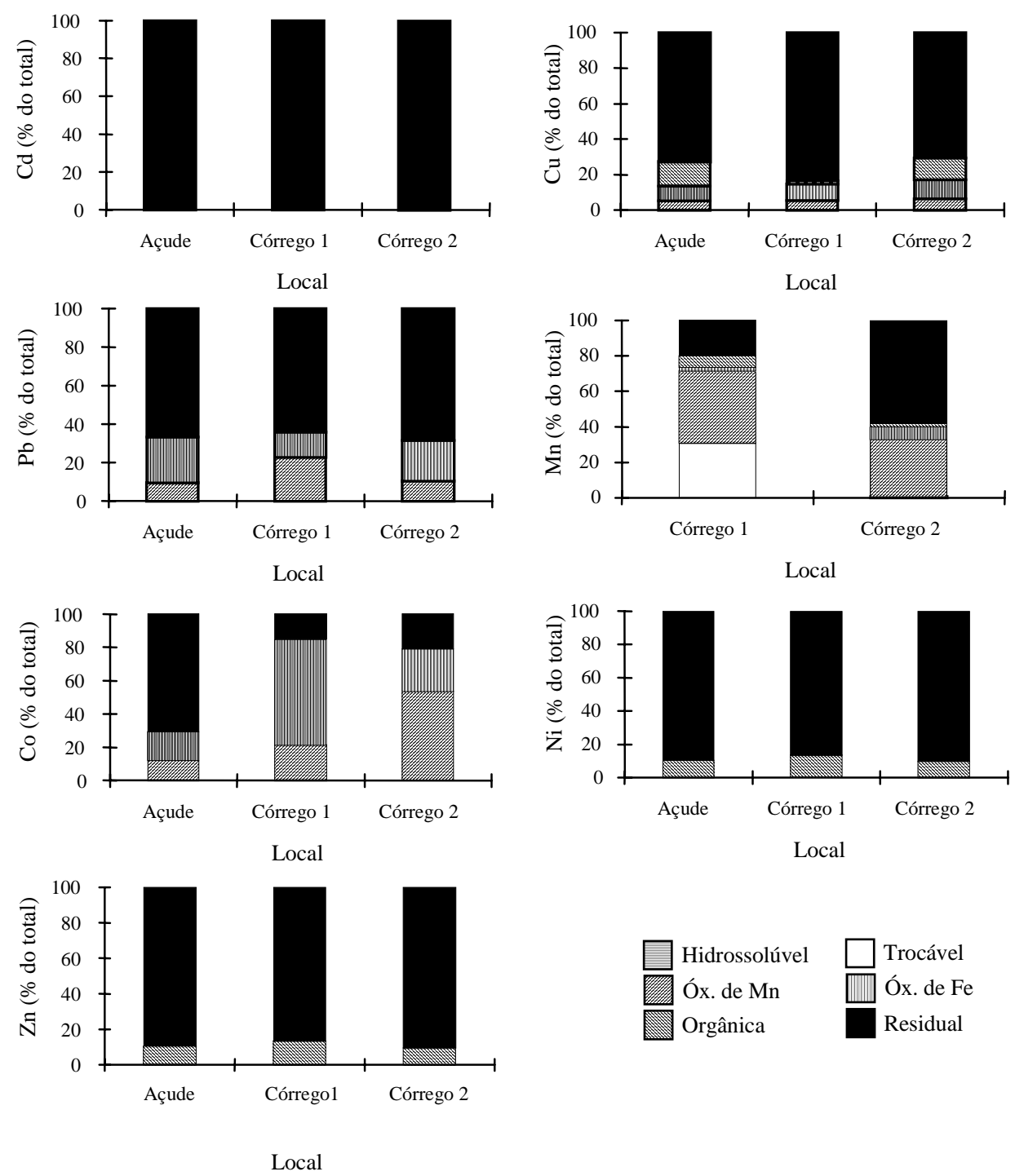

FIG. 7. Distribuição porcentual de $\mathrm{Cd}, \mathrm{Co}, \mathrm{Cu}, \mathrm{Ni}, \mathrm{Mn}, \mathrm{Pb}$ e $\mathrm{Zn}$ nas frações de sedimentos da microbacia de Caetés, Paty do Alferes, RJ. 
TABela 6. Teores totais de $\mathrm{Zn}, \mathrm{Cd}, \mathrm{Ni}, \mathrm{Pb}, \mathrm{Co}, \mathrm{Cu}$ e $\mathrm{Mn}$ em amostras de água da microbacia de Caetés, Paty do Alferes, RJ'1 . Média de três repetições.

\begin{tabular}{|c|c|c|c|c|c|c|c|}
\hline Local & $\mathrm{Zn}$ & $\mathrm{Cd}$ & $\mathrm{Ni}$ & $\mathrm{Pb}$ & Co & $\mathrm{Cu}$ & $\mathrm{Mn}$ \\
\hline & & & & $\left.n g L^{-1}\right)$ & & & ----י-- \\
\hline Córrego 1 & $0,34 \mathrm{C}$ & $0,11 \mathrm{~B}$ & $0,65 \mathrm{~A}$ & $0,02 \mathrm{C}$ & $0,06 \mathrm{~A}$ & $0,13 \mathrm{C}$ & $0,23 \mathrm{C}$ \\
\hline Córrego 2 & $0,90 \mathrm{~B}$ & $0,14 \mathrm{~A}$ & $0,66 \mathrm{~A}$ & $0,08 \mathrm{~A}$ & $0,02 \mathrm{~B}$ & $0,22 \mathrm{~B}$ & $0,72 \mathrm{~A}$ \\
\hline Açude & $1,70 \mathrm{~A}$ & $0,09 \mathrm{C}$ & $0,46 \mathrm{~B}$ & $0,06 \mathrm{~B}$ & $0,02 \mathrm{~B}$ & $0,28 \mathrm{~A}$ & $0,33 \mathrm{~B}$ \\
\hline Conc. máxima ${ }^{2}$ & 5,0 & 0,005 & - & 0,05 & - & 1,0 & 0,1 \\
\hline
\end{tabular}

${ }^{1}$ Médias com mesma letra não diferem estatisticamente entre si a 5\% de probabilidade, pelo teste de Tukey.

${ }^{2}$ Concentrações máximas permitidas em água potável segundo Brasil (1990).

sedimentos. As concentrações de $\mathrm{Cd}, \mathrm{Pb}$ e $\mathrm{Mn}$, em comparação com os padrões de potabilidade de água estabelecidos pelo Brasil (1990), ficaram bem acima do permitido, o que mostra elevação dos teores desses metais com o uso agrícola da microbacia.

\section{CONCLUSÕES}

1. Os solos da microbacia de Caetés, que receberam aplicação intensiva de agroquímicos, mostram aumento nos teores totais de metais pesados, que, contudo, não atingem os níveis críticos estabelecidos em solos, além de estarem distribuídos em formas químicas pouco disponíveis para a absorção pelas plantas.

2. A água do córrego e do açude da microbacia de Caetés apresenta teor total de $\mathrm{Cd}, \mathrm{Mn}$ e $\mathrm{Pb}$ acima dos padrões máximos estabelecidos em água potável pelo Ministério da Saúde.

3. Os sedimentos retirados do córrego da microbacia de Caetés mostram incrementos nos teores totais de metais pesados, de acordo com a posição de coleta na área; entretanto, esses metais não estão presentes em formas químicas biodisponíveis às plantas.

4. As análises de plantas cultivadas na microbacia de Caetés mostram baixos índices de absorção de metais pesados, estando os valores dentro dos padrões normais estabelecidos em plantas.

5. A topografia da área e seu uso agrícola têm um efeito marcante na acumulação de metais pesados no solo: quanto menor a declividade e mais freqüente o uso de agroquímicos, maior o teor de metais pesados nas camadas superficiais do solo.

\section{REFERÊNCIAS}

ALLOWAY, B.J. Appendices. In: ALLOWAY, B.J. (Ed.). Heavy metals in soils. Glasgow : Blackie and Son, 1990a. p.322-330.

ALLOWAY, B.J. Soil processes and the behaviour of metals. In: ALLOWAY, B.J. (Ed.). Heavy metals in soils. Glasgow : Blackie and Son, 1990b. p.7-27.

BAKER, D.E. Copper. In: ALLOWAY, B.J. (Ed.). Heavy metals in soils. Glasgow : Blackie and Son, 1990. p.51-74.

BLUME, H.P.; BRÜMMER, G. Prediction of heavy metal behaviour in soil by means of simple field tests. Ecotoxicology and Environmental Safety, San Diego, v.22, p.164-174, 1991.

BRASIL. Ministério da Saúde. Normas e padrão de potabilidade de água destinada ao consumo humano. Portaria 6M/36/1990. Diário Oficial (da República Federativa do Brasil), Brasília, 23 jan. 1990. Seção 1, p. 1651 .

BUBB, J.M.; LESTER, J.N. Anthropogenic heavy metal inputs to lowland river systems, a case study: the river Stour, U.K. Water, Air and Soil Pollution, Dordrecht, v.78, p.279-296, 1994.

CAÑADAS, R.C.; SANCHIDRIAN, J.R.; RIVERO, V.C. Distribución de $\mathrm{Pb}, \mathrm{Cd}, \mathrm{Cu}$ y $\mathrm{Cr}$ entre distintas fases sólidas en algunos tipos de suelos. Anales de Edafologia y Agrobioliologia, Madrid, v.45, p.613630, 1986.

EMBRAPA. Serviço Nacional de Levantamento e Conservação de Solos (Rio de Janeiro, RJ). Manual de métodos de análise de solo. Rio de Janeiro, 1979. não paginado. 
FERNANDES, M.R. Estudos pedológicos de topossequiências na microbacia do Córrego da Cachoeira, Paty do Alferes (RJ). Seropédica : UFRRJ, 1998. 204p. Tese de Doutorado.

FISZMAN, M.; PFEIFFER, W.C.; LACERDA, L.D. Comparison of methods used for extraction and geochemical distribution of heavy metals in bottom sediments from Sepetiba bay, R.J. Environmental Technology Letters, London, v.5, p.567-575, 1984.

FRANK, R.; ISHIDA, K.; SUDA, P. Metals in agricultural soils of Ontario. Canadian Journal of Soil Science, Ottawa, v.56, p.181-196, 1976.

FUNDAÇÃO ESTADUAL DE ENGENHARIA DO MEIO AMBIENTE (Rio de Janeiro, RJ). Manual do meio ambiente. Rio de Janeiro, 1979. 126p.

GIMENO-GARCÍA, E.; ANDREU, V.; BOLUDA, R. Heavy metals incidence in the application of inorganic fertilizers and pesticides to rice farming soils. Environmental Pollution, Kidlington, v.92, n.1, p.19-25, 1996.

HE, Q.B.; SINGH, B.R. Effect of organic matter on the distribution, extractability and uptake of cadmium in soils. Journal of Soil Science, Oxrford, v.44, p.641-650, 1993.

IBGE (Rio de Janeiro, RJ). Distribuição por nome técnico de agrotóxicos. Caderno de Geociências, Rio de Janeiro, n.13, p.152, jan./mar. 1995.

KABATA-PENDIAS, A.; PENDIAS, H. Trace elements in soils and plants. Boca Raton : CRC, 1984. 315p.

KELLER, C.; VÉDY, J.C. Distribution of copper and cadmium fractions in two forest soils. Journal of Environmental Quality, Madison, v.23, n.5, p.987999, 1994.

KIEKENS, L. Zinc. In: ALLOWAY, B.J. (Ed.). Heavy metals in soils. Glasgow : Blackie and Son, 1990. p.261-277.
LACERDA, L.D.; CARVALHO, C.E.V.; REZENDE, C.E.; PFEIFFER, W.C. Mercury in sediments from the Paraíba do Sul river continental shelf, S.S. Brazil. Marine Pollution Bulletin, Oxford, v.26, n.4, p.220-222, 1993.

LACERDA, L.D. Heavy metal pollution in soil and plants of the Irajá river estuarine area in the Guanabara bay. Revista Brasileira de Biologia, Rio de Janeiro, v.42, n.1, p.89-93, fev. 1982.

MALM, O.; PFEIFFER, W.C.; FISZMAN, M.; AZENE, J.M.P. Heavy metal concentrations and availability in the bottom sediments of the Paraíba do Sul-Guandu river system, RJ, Brazil. Environmental Technology Letters, London, v. 10, p.675-680, 1989.

PETRUZZELLI, G.; LUBRANO, L.; GUIDI, G. Uptake by corn and chemical extractability of heavy metals from a four-year compost treated soil. Plant and Soil, Dordrecht, v.116, p.23-27, 1989.

PEZZAROSSA, B.; PETRUZZELLI, G.; MALORGIOF, F.; TOGNONI, F. Effect of repeated phosphate fertilization on the heavy metal accumulation in soil and plants protected cultivation. Communications in Soil Science and Plant Analysis, New York, v.24, n.17/18, p.1307-2319, 1993.

SPOSITO, G. The chemistry of soils. New York : Oxford University Press, 1989. 234p.

TILLER, K.G. Heavy metals in soils and their environmental significance. In: TILLER, K.G. Advances in soil science. New York : Springer, 1989. v.9, p.113-114.

XIAN, X. Chemical partitioning of cadmium, zinc, lead, and copper in soils near smelter. Journal of Environmental Science and Health, Part A, v.22, p.527-541, 1987. 